\title{
Type VI Choledochal Cyst; A Case Report and Review of the Literature
}

\author{
Serdar Aslan* (D), Ömer Görgel(D) and İsmet Miraç Çakır(D)
}

\begin{abstract}
Background: Choledochal or common bile duct (CBD) cysts are congenital cystic dilatation of any part of the bile ducts. It has been classified into five main types by Todani et al. Isolated cystic duct cysts are not included in this classification. It is extremely rare, and there are a limited number of cases in the literature.

Case presentation: A 34-year-old male patient was admitted to our hospital with right upper quadrant (RUQ) pain experienced intermittently for the past year. His medical history and laboratory findings were normal. Physical examination revealed tenderness in the RUQ. Abdominal ultrasonography shows that a thin, tubular, cystic lesion was associated with the CBD. On magnetic resonance imaging (MRI) and magnetic resonance cholangiopancreatography (MRCP), a saccular dilatation was observed in the middle part of the cystic duct. Isolated cystic duct dilatation was considered with current imaging findings. Laparoscopic cholecystectomy and cyst excision were performed. Surgery findings and histopathological examination of the excised cyst confirmed the diagnosis.

Conclusion: Isolated dilatations of the cystic duct are extremely rare, and familiarity with this anatomic variation and its early diagnosis can prevent complications such as inflammation and malignancy and guide the surgery. The most effective noninvasive imaging method in diagnosis is MRCP. Also, we recommend that it be classified as a new type with the name type VI biliary cyst, in addition to Todani classification.
\end{abstract}

Keywords: Choledochal cyst, Todani classification, Type VI biliary cyst, Magnetic resonance cholangiopancreatography

\section{Background}

Choledochal or common bile duct (CBD) cysts are congenital cystic dilatation of any part of the bile ducts, regardless of stone, tumor, or inflammation. The incidence reported in the literature is $1: 100,000$ to 150,000 live births [1]. Traditionally, it has been classified into five main types by Todani et al. [2]. Isolated cystic duct cysts are not included in this classification. It is extremely rare, and there are a limited number of cases in the literature. The first case was reported in 1991 by Serradel et al. reported and named as "type VI biliary cyst" [3]. We propose to present imaging findings of a type VI biliary cyst we detected in a case referred to us due to

\footnotetext{
* Correspondence: serdaraslan28@hotmail.com

Department of Radiology, Faculty of Medicine, Giresun University, Giresun, Turkey
}

SpringerOpen

(c) The Author(s). 2020 Open Access This article is licensed under a Creative Commons Attribution 4.0 International License which permits use, sharing, adaptation, distribution and reproduction in any medium or format, as long as you give appropriate credit to the original author(s) and the source, provide a link to the Creative Commons licence, and indicate if changes were made. The images or other third party material in this article are included in the article's Creative Commons licence, unless indicated otherwise in a credit line to the material. If material is not included in the article's Creative Commons licence and your intended use is not permitted by statutory regulation or exceeds the permitted use, you will need to obtain permission directly from the copyright holder. To view a copy of this licence, visit http://creativecommons.org/licenses/by/4.0/.

\section{Case presentation}

A 34-year-old male patient was admitted to our hospital with right upper quadrant pain (RUQ) experienced intermittently for the past year, each episode of which had a duration of approximately 1 week. There was no history of fever, jaundice, and weight loss. Physical examination revealed no abnormality except for tenderness in the RUQ. Hemogram and blood chemistry were normal. On abdominal ultrasonography (US), which was performed to investigate etiology, the gallbladder was normal. A thin, tubular, cystic lesion of $32 \times 16 \mathrm{~mm}$ was associated with the CBD. The patient underwent 
magnetic resonance imaging (MRI) and magnetic resonance cholangiopancreatography (MRCP) to further investigate US findings and to determine the relationship of the cystic lesion to surrounding structures. On MRI and MRCP, a saccular dilatation measuring $35 \times 23 \mathrm{~mm}$ was observed in the middle part of the cystic duct (Fig. 1). The gallbladder, intrahepatic bile duct, other sections of the cystic duct, and extrahepatic bile ducts were normal (Fig. 1). There was a narrow connection between the CBD and the distal section of the cystic duct. Abnormal pancreaticobiliary ductal junction (APBDJ) was not observed. The diagnosis of isolated cystic duct cyst was made with the available images. The patient was taken to surgery. On laparoscopic surgery, saccular dilatation was observed in the middle part of the cystic duct; cholecystectomy and cyst excision were performed. Histopathological examination of the excised cyst confirmed the diagnosis. The patient was discharged on the fourth postoperative day without any problem. Written informed consent was obtained from the patient for publication of this case report and accompanying images.

\section{Discussion}

CBD cysts are classified into five categories as described by Todani et al. Type I is cyst of the extrahepatic bile duct only; type II is a supraduodenal CBD diverticulum; type III is a choledochocele; type IV refers to multiple dilatations in the intra- and extrahepatic bile ducts; type $\mathrm{V}$ is single or multiple cysts in the intrahepatic bile ducts without extrahepatic bile ducts, which is known as Caroli disease [2]. Type VI biliary cysts are rare and are not included in the Todani classification. A very limited number of reports in the literature mainly consist of single case reports, and to our knowledge, only one review has been done [4].

The most accepted theory for the development of CBD cysts is APBDJ, which occurs in approximately $40 \%$ of cases [5]. In the cases of APBDJ, the CBD and pancreatic ducts merge more proximally than normal, opening to the Oddi sphincter. This causes reflux of pancreatic enzymes to the $\mathrm{CBD}$ and leads to weakening and cystic dilatation in the CBD wall. However, not all CBD cysts are accompanied by APBDJ, and sometimes APBDJ can be seen when CBD cysts are absent. This situation suggests that, more than one mechanism is responsible for the development of CBD cysts [6, 7]. Amarjothi et al. argued that cystic duct cysts may result from a combination such as APBDJ, acute angulation, and cystic ductCBD connection with a wide opening [8]. However, in most cases reported in the literature and in our case, APBDJ, angulation, and wide opening of the cystic duct to the CBD were not observed. More research is needed to evaluate other factors that may be responsible.

Clinical symptoms of cystic duct cysts are often similar to other CBD cysts. They can also be asymptomatic and detected incidentally. When symptomatic, they often occur with RUQ and epigastric pain. Apart from this, they can occur with complications such as jaundice, cholangitis, and gallstone disease, depending on the size of the cyst and the pressure effect it creates [9]. Although the most feared complication is cholangiocarcinoma arising from the cyst itself, it is rare [10]. In our case, there was intermittent recurrent RUQ pain, but no signs of complication were detected.

Due to their rarity, type VI biliary cysts are often not diagnosed preoperatively or are misdiagnosed. Most known cases were diagnosed intraoperatively $[5,6,10]$. Type VI biliary cysts can be seen in a variety of ways. Fusiform or saccular dilatation can be seen in the cystic duct, without any dilatation in other bile ducts, or fusiform cystic duct dilatation can be observed with a varying relationship between dilated CBD and the cyst [10]. Radiological imaging is very useful in preoperative diagnosis. US is often the first choice method. A non-vascular dilated cystic lesion is detected at the level of the porta hepatis. In such a case, an attempt should be made to show the relation of the cystic lesion to the bile ducts, gallbladder and CBD. However, US is operator-dependent, and it may not be possible to demonstrate these relationships in the presence of inflammatory conditions. Endoscopic retrograde cholangiopancreaticography (ERCP) is

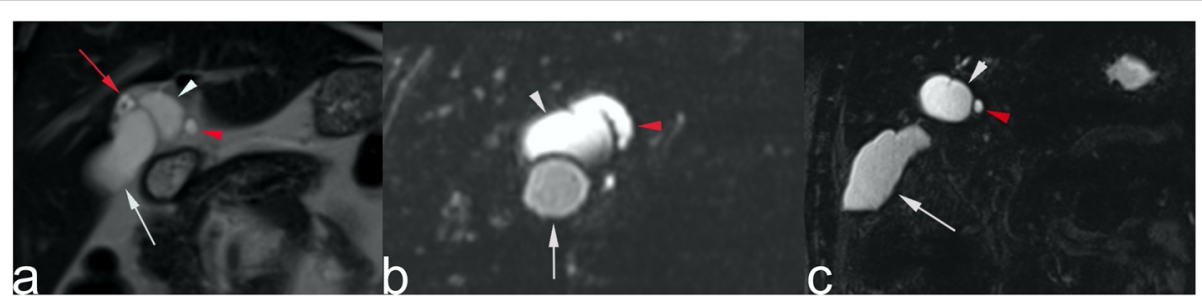

Fig. 1 a On T2-weighted images, saccular dilatation is observed in the middle part of the cystic duct (type VI biliary cyst) (white arrowhead). The gallbladder (white arrow) and the proximal (red arrow) and distal cystic duct (red arrowhead) are normal. b On axial and c coronal MRCP images, similar to T2-weighted images, saccular dilatation is observed in the middle part of the cystic duct (white arrowhead). It is seen that the gallbladder (white arrow) and distal cystic duct (red arrowhead) are normal and distal cystic duct relationship with cystic dilatation is more clear 
the gold standard in diagnosis, but it is invasive. Apart from this, it requires sedation, and there are risks of complications such as biliary sepsis, cholangitis, pancreatitis, perforation, and contrast allergy. MRCP, which is noninvasive and radiation-free, can be used as an equivalent to ERCP for diagnosis with excellent resolution in demonstrating the biliary tract. MRCP helps to detect the localization of the cyst, its relationships, the presence of possible APBDJ, and complications [8, 10]. ERCP is indicated when MRCP is insufficient or when a therapeutic procedure is required. In our case, the cystic lesion was detected by US, but the localization relationships could not be determined clearly. On MRCP, the diagnosis was made accurately, and there was no need for ERCP.

Management of type VI biliary cysts is guided by morphology $[1,8]$. Early and accurate radiological diagnosis is very important to prevent complications and to choose an appropriate surgical method. In case of a narrow connection to the CBD, cyst excision and cholecystectomy are sufficient. However, in cases where there is a wide connection to the CBD, hepaticojejunostomy should be performed in addition to the above procedures $[8,10]$. In our case, since there was a narrow connection between the cystic duct and the CBD, cholecystectomy and cyst excision were performed laparoscopically, and the patient was discharged without any problem after surgery.

\section{Conclusion}

Isolated dilatations of the cystic duct are extremely rare, and familiarity with this anatomic variation and its early diagnosis can prevent complications such as inflammation and malignancy and guide the surgery. The most effective noninvasive imaging method in diagnosis is MRCP.

\section{Abbreviations}

CBD: Common bile duct; RUQ: Right upper quadrant; MRI: Magnetic resonance imaging; MRCP: Magnetic resonance cholangiopancreatography; US: Ultrasonography; APBDJ: Abnormal pancreaticobiliary ductal junction; ERCP: Endoscopic retrograde cholangiopancreaticography

\section{Acknowledgements}

None

\section{Authors' contributions}

SA contributed to the data acquisition, manuscript preparation, and approval of the final version of the study. ÖG contributed to the oversight over the case report, data acquisition, and approval of the final version of the study. IMC contributed to the manuscript preparation, revision of the manuscript and final edit, interpretation of imaging findings, and approval of the final version of the manuscript. All authors have read and approved the manuscript.

\section{Funding}

No one was paid during this study. The study did not have a source of funding. This study was not supported by a grant.

\section{Ethics approval and consent to participate}

This study was approved by the ethics committee of Giresun University (reference number 2020-099765). The patient reported in this article had signed a written informed consent form. This case report was a reporting of a case in a medical educational center, in which all patients are informed that they may be subjects of scientific experiments and are informed of the ethical codes of conducts. This study was in compliance to the latest version of the Helsinki Declaration.

\section{Consent for publication}

The patient had written and signed an informed consent note that the findings may be published without any personal detail.

\section{Competing interests}

The authors declare that they have no competing interests.

Received: 26 February 2020 Accepted: 9 June 2020

Published online: 23 June 2020

\section{References}

1. Singham J, Yoshida EM, Scudamore CH (2009) Choledochal cysts: part 1 of 3: classification and pathogenesis. Can J Surg 52:434-440

2. Todani T, Watanabe Y, Narusue M, Tabuchi K, Okajima K (1977) Congenital bile duct cysts. Classification, operative procedures, and review of thirtyseven cases including cancer arising fromcholedochal cyst. Am J Surg 134(2):263-269

3. Serena Serradel AF, Santamaría Linares E, Herrera Goepfert R (1991) Cystic dilatation of the cystic duct: a new type of biliary cyst. Surgery 109:320-322

4. Maheshwari P (2012) Cystic malformation of cystic duct: 10 cases and review of literature. World J Radiol 4(9):413-417

5. Bheerappa N, Sastry RA (2001) Pancreatico-biliary ductal union. Trop Gastroenterol 22:190-193

6. Hae KL, Seong JP, Bum HY, Lee AL, Jong HM, Yun WC (2009) Imaging features of adult choledochal cysts: a pictorial review. Korean J Radiol 10(1): $71-80$

7. Singham J, Schaeffer D, Yoshida E, Scudamore C (2007) Choledochal cyst: analysis of disease pattern and optimal treatment in adult and paediatric patients. HPB (Oxford) 9:383-387

8. Amarjothi JMV, Ramasamy V, Jesudasan J, NaganathBabu OL (2019). Type VI choledochal cysts-case report and review of literature. Surg J 23;5(3):82-86

9. Loke TKL, Lam SH, Chan CS (1999) Choledochal cyst an unusual type of cystic dilatation of the cystic duct. Am J Roentgenol 173(3):619-620

10. Vishwanath RV, Kumar A, Aggarwal M, Kurdia KC (2019) Type IV choledochal cyst with gall bladder carcinoma. BMJ Case Rep 29(12):12

\section{Publisher's Note}

Springer Nature remains neutral with regard to jurisdictional claims in published maps and institutional affiliations.

\section{Submit your manuscript to a SpringerOpen ${ }^{\circ}$ journal and benefit from:}

- Convenient online submission

- Rigorous peer review

- Open access: articles freely available online

- High visibility within the field

- Retaining the copyright to your article

Submit your next manuscript at $\boldsymbol{\nabla}$ springeropen.com 